neither before nor since has the magnetic field of the earth been subjected to a corresponding control. Hence practically all the more recent theoretical investigations in this field have been based wholly or partly on the recordings of the Polar Year. In the Polar Year observations the application of a supplementary recording device with manifold paper-speed made it possible to study even the most rapid variations of the magnetic field, while at the same time the exact timing made it possible to draw more accurate conclusions as to the degree of simultaneousness with which world-wide magnetic disturbances occur at different points on the surface of the earth. The extensive use of this new type of instrument was made possible through the most generous support by the Rockefeller Foundation.

At the same time as the variations of the geomagnetic field were thus being observed on an unprecedented scale, detailed observations of auroras were undertaken at all stations in higher latitudes, thus providing extensive material for the elucidation of the interrelation between these two phenomena.

The propagation of radio waves over various parts of the earth and the variation of propagation with geomagnetic or other disturbances were also studied in detail through specially arranged international radio broadcasts, which at specified hours were received by a large number of stations all over the world.

Many other investigations, for example, investigations in atmospheric electricity, earth currents and cosmic radiation, formed to a greater or smaller extent part of the observational programmes of the individual stations. Such investigations, which, of course, in themselves are of scientific value, gain increased importance during the Polar Year, since they were undertaken concurrently with investigations of other phenomena from adjacent geophysical regions, so that it becomes possible to trace any interrelation with these phenomena; further, since the investigations were undertaken simultaneously over large areas of the earth, it is possible to decide whether a phenomenon is of a purely local or perhaps of a world-wide character.

It is in full harmony with the international character of the Polar Year that, in planning the work to be undertaken, exceedingly great weight was attached to the fact that the observations were to be made available for all men of science interested, and during the years following the Polar Year a very large number of valuable publications has been issued. The first to be published were expedition reports and reports from institutions all over the world which had taken part in some way or other in the work and which now made their observations available for scientific research. There followed in rapid succession papers and treatises based on the observations published, showing that the expecta. tions with which the results of the Polar Year had been awaited had not been exaggerated.

No doubt it will be possible to build for a long time to come on the observations of the Polar Year, as well as on the analyses of this material already available. This will, however, require that the scientific workers who are to-day working on geophysical subjects-and who already belong partly to a generation younger than the one which planned and carried through the Polar Year-should be able to obtain a comprehensive view of the existing material of analysed and unanalysed observations, as well as of the number of scientific treatises on them already published. The International Commission of the Polar Year was formally dissolved when the International Meteorological Organisation met for the first time after the War (London, 1946); but at the following meeting of the International Meteorological Committee (Paris, 1946) a Temporary Commission was set up, charged with the task of completing and rounding off the work of the Commission of the Polar Year. This Temporary Commission has been charged, inter alia, with the preparation of a bibliography of all publications relating to the Polar Year. Dr. J. A. Fleming, Carnegie Institution, Washington, is president of the Commission, and a special Central Bureau has been established at the Danish Meteorological Institute, where Dr. la Cour had already before the War collected very extensive records on the Polar Year. The Rockefeller Foundation has renewed an appropriation which had been granted earlier in support of the continued work of the Commission of the Polar Year, but which on account of the War it had not been possible to utilize. The greater part of these funds will be used for the preparation and printing of the bibliography mentioned above. Institutions and scientific workers, who in any way have contributed towards the accomplishment of the programme of the Polar Year or have benefited from the results of the Polar Year, are asked to assist the Central Bureau in its efforts to make the bibliography as complete as possible.

The work of the Temporary Commission is to be completed by the end of 1950 , and it is to be hoped that the results of its work may prove beneficial to the men of science who may be expected for many years to come to resort to the almost inexhaustible fund of observations from the Polar Year in such cases where the solution of a geophysical problem requires a uniform, simultaneous material of observations from the entire surface of the earth.

\section{MODERN METHODS OF MINERAL EXPLORATION}

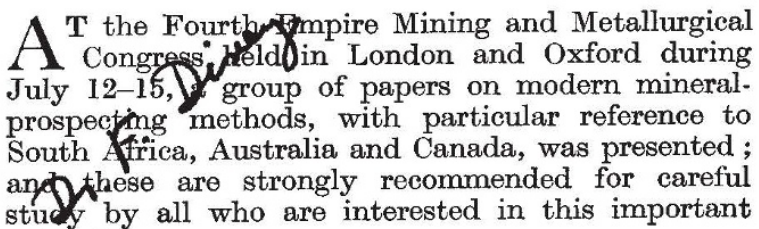
subject'.

One paper ${ }^{2}$ was devoted to the use of aerial photography in the production of geological maps and in the direction of mineral exploration. It is emphasized that photogeology should not be regarded as a substitute for field-work, but rather as a basis for the efficient and economical organisation of field operations. The amount of geological information that can be obtained from photographs of an area will depend mainly on how closely the morphology of the area reflects the structure and lithology of the underlying rocks. Five photogeological maps are given to illustrate what can be accomplished in areas of differing geology and climate.

The methods of mineral exploration now in general use are mainly geological and geophysical, supplemented by an extensive use of test drilling at carefully selected sites. The authors discuss the modern development of these techniques. 
In most countries the more obvious mineral deposits have already been discovered, and the modern prospector is faced with the far more difficult task of tracking down deposits that make very little show at the surface or may even be wholly concealed. In some countries, however, notably Canada, there is still place for the older prospecting methods of panning, tracing 'float', noting actual outcrops and mineral stains, etc. ; and the present-day prospector is given every assistance by means of courses of study, publications and maps. In the less well-known parts of many Colonial territories, also, there is scope for search along these lines.

In general, however, modern mineral prospecting has to rely on scientific methods of exploration. The production of a geological map-the more detailed the better-and the application of geological knowledge and methods, assisted by aerial survey, geophysics, geochemistry and other new techniques, based upon scientific principles, as auxiliary tools, offer almost the only means of finding new ore bodies.

The geological map is fundamental to any systematic and efficient search for new mineral deposits or for determining possible extensions of known ore-bodies. By means of geological mapping it is usually possible to delineate mineralized areas, and geological mapping provides also the requisite knowledge for the interpretation of the results obtained by geophysical surveying.

The geophysicist has at his disposal four main methods - magnetic, seismic, gravimetric and electrical - in his search for mineral deposits, and the primary object before commencing a survey is to determine, from what is already known about the geology, which method or which combination of methods is most likely to give the desired information. In order to obtain the best results it is essential that the interpretation of the available data is made by the geologist and the geophysicist working in close collaboration. Most geophysical methods do not directly locate ore; they locate structures and formations with which ore is likely to be associated.

Magnetic Method. The magnetic method of prospecting is one of the cheapest and most rapid methods available. It utilizes a natural field of force and depends for its results on detecting variations in the earth's magnetic field occasioned by the presence of magnetic bodies.

In Canadian mineral exploration, magnetic methods have been more widely applied than any other geophysical tool, because they are usually less affected by interfering surface features and because, in general, there exists a broad relationship between rock types and their magnetic properties. Thus, magnetic methods permit a generalized outlining of the rock bodies present, for geological study, deductions and guidance.

Magnetic measurement methods have been applied underground and in drill holes, and the magnetic method is now being practised with air-borne instruments, using both standard and helicopter aireraft.

In Canada the magnetic method has led to the discovery of the Quemont copper gold ore-body, the copper zine ore-body at East Sullivan, and nickelcopper ore-bodies in Manitoba and elsewhere. In South Africa it was widely applied in the discovery of extensions of the Witwatersrand beds and the new Orange Free State goldfields. It has been used also to delineate post-Coal Measures dykes that have burnt considerable areas of coal on their flanks. It assisted, too, in the discovery of iron ore deposits, in tracing the boundaries of diamond pipes and fissures extending from them, in the investigation of sulphide ore-bodies, and in tracing extensions of the chrome deposits of the northern Transvaal.

During the Second World War the development of the magnetic airborne detector represented an important advance in applied geophysics. This detector, primarily designed to locate submarines by detecting their magnetic field, has now been adopted for magnetometric prospecting. With it, magnetic surveys can be carried out at the speed of the aeroplane, which is of the order of 200 miles an hour. Magnetic surveys can be undertaken over terrain hitherto inaccessible and with an accuracy as great as, if not greater than, that obtained by ground measurements. If the area to be investigated is sufficiently large, the cost per mile of traverse is less than by ground methods. A correct interpretation of the anomalies revealed is, however, dependent on adequate geological knowledge of the area surveyed.

Gravitational Methods. Gravitational methods of surveying involve the measurement of variations in the earth's field of gravitation occasioned by the presence of bodies of density different from that of their surrounding medium. Surveys are made by one or more of the following three methods: (1) pendulum measurements; (2) torsion balance measurements; (3) gravimeter measurements. Of these three, the last two are more commonly used, and the tendency has been in recent years for the gravimeter to replace the torsion balance for many purposes. The time taken to observe one torsion balance station is approximately three hours, whereas the gravimeter, which measures the actual value of the vertical component of gravity at each station, requires only a few minutes to take an observation and is therefore a much less expensive instrument to use. In South Africa, extensive gravitational exploration has been carried out in and around the goldfields of the Orange Free State. Used in conjunction with magnetic methods, which located magnetic bands presumably in Lower Witwatersrand beds, these surveys have, with the help of drilling, discovered the Witwatersrand system, carrying auriferous conglomerates, in an area where there was no single outcrop within sixty miles to indicate what rocks might occur beneath the cover of Karroo beds. Gravitational methods are of great value also in locating faults and in the delineation of major contacts, such as that of the denser portions of the Witwatersrand system with the granite. They were used also to discover possible suitable structures for exploratory drilling in an oil survey.

Seismic Methods. Seismic methods of prospecting are dependent on differences in the speed of transmission of elastic waves through the crust of the earth. The travel-times of waves are observed with seismometers placed at various distances from the shock point. Seismic methods are used mainly in oilfield surveys, but are often used as an adjunct to other methods of mineral exploration. In Canada, seismic work has been almost exclusively confined to determining the depth of drift or depth to basement formations.

Electrical Methods. The application of electrical methods to the direct location of conducting orebodies is limited owing to the masking effect of the varying resistivities of the country rock in which the lodes occur. Electrical resistivity methods have 
none the less been of use in South Africa as, for example, in locating pyritic deposits developed in schists, schist horizons which carry tungsten, in determining the depth of alluvial tin depths, and the approximate depth of a vermiculite deposit; they are of great value also in ground-water investigations. The self-potential method is probably one of the oldest of geophysical methods and can be employed for the location of certain sulphide ore-bodies. Oxidation, due to contact with underground water, makes the ore-body act as a large galvanic cell with one pole in the upper portion of the body. Considerable potential differences may be set up, and a centre is located in the field which normally lies above the ore-body. In Canada, some of the Noranda sulphide ore-bodies were indicated in this way, as well as a small copper ore-body at Moulton Hill, Quebec.

Radioactivity Measurements. Radioactivity methods of prospecting fall into the category of direct methods since they detect radioactive ores by means of the emanation from the material itself. As a prospecting method, however, this method is restricted, as even the hardest emanation from a deposit of radioactive ore is absorbed by a few inches of barren rock, so that the instruments can only be of use in detecting deposits at or near an exposed surface.

Recent research work by the South African Council for Scientific and Industrial Research has resulted in the development of equipment whereby radioactivity measurements may now be made in bore-holes of a maximum diameter of $1 \frac{3}{4}$ in., using a single-core cable for transmission of the impulses from the counter.

In Canada the radioactivity surveys have been largely confined to prospecting for uranium, and Geiger counters and ionization chambers during the past year alone have directly discovered uraniumbearing occurrences in Ontario, Saskatchewan, the North-West Territories, and British Columbia. This prospecting technique has been applied on the surface, down drill holes, and at Great Bear Lake under $200 \mathrm{ft}$. of water. Gamma-ray detection by Geiger-type 'Pentron' tube is now possible from an aircraft.

Geochemical Methods. Geochemical methods depend on the micro-analysis of carefully selected parallel samples of soil, humus, rock debris, plant parts, or ground waters for abnormal traces of given elements, such as copper, zine, lead, gold and beryllium. Analyses may take the form of vapour are spectra and densitometer measurements, chemical analyses, colorimetric tests, solid residue content, radioactivity, etc., depending on the nature of the problem and the material sought.

Applications of the geochemical technique to ore search are still few in Canada ; but research work in this field is active and increasing. Recent research in five important British Columbia metal-mining camps indicates that there is ground for optimism in the application of this technique. V. P. Solzoloff, of the United States Geological Survey, under contract to Zinc Corporation, Ltd., and the Australian Bureau of Mineral Resources, in 1948 carried out extensive geochemical studies in the Wallaroo Moonta area, South Australia, and he used dithizone to detect copper dispersed in the deep residual soils of this mineralized district. The dithizone technique is being applied, too, to the detection of very small quantities of gold above the hæmatite masses of Tennant Creek, Northern Territory, Australia. Geochemical methods are being employed also in Nigeria in the investigation of lead-zine deposits.
Laboratory services and research also contribute a great deal to modern methods of mineral exploration. In addition to the customary assaying and chemical analyses of mineral samples, ore-dressing and metallurgical research are also undertaken. Moreover, some laboratories are equipped for spectrographical analyses, radioactivity detection and measurement, and X-ray diffraction studies.

Drilling is an essential adjunct to mineral exploration, since the presence of mineral deposits under cover of other rocks, whether inferred from geological or geophysical observations, or by other reasonings, can often be confirmed only by this means. Extensive diamond-drilling exploration, based upon geological and geophysical deductions, has added considerably to our knowledge of ore reserves; in South Africa, for example, the more striking discoveries by this means include the extension of the Witwatersrand gold-field, new gold discoveries near Klerksdorp, the Odendaalsrus gold-field, and a hidden coal-field in the Waterberg district. In Canada, also, drilling in recent years has produced very important results. An unusual mode of diamond drilling, but one quite common in the pre-Cambrian areas of the Canadian North-West Territories, is that of drilling from the ice on frozen lake surfaces. Occasionally lake bottoms are diamond-drilled on the basis of lake-shore float discoveries, or from geological or geophysical observations. Such drilling can be very conveniently and expeditiously performed over a three- or four-month winter period each year.

In addition to drills, several heavy mechanical devices play an important part in mineral exploration. These include bulldozers for surface stripping for purposes of geological study, portable air compressor equipment, and high-pressure pumping equipment for sluicing. In Canada, owing to the vast distances and lack of normal communications, remote mining camps are supplied by Diesel-driven sleigh trains which, in the winter, travel day and night over frozen wastes. At other times equipment is dropped from aircraft on to snow or meadows, sometimes without parachutes.

In one of the papers reviewed, C. J. Sullivan has given a very interesting account of the mineral exploration methods employed in Australia in recent years. In the second half of the last century much important mining activity resulted from discoveries by ordinary prospecting methods; but the rate of discovery of new deposits by such methods in the present century has been quite discouraging. In order to stimulate the search for new mineral deposits by modern methods the Commonwealth Government, besides introducing taxation reforms, has set up the Bureau of Mineral Resourees, Geology and Geophysics. The Bureau was created in 1946 and now has an establishment of approximately sixty geologists and sixty geophysicists, as well as small sections devoted to mineral economics, petroleum technology, geochemistry, drilling and mining engineering.

The Bureau is designed to take an active part in mineral exploration, and its programmes of research have been co-ordinated with those of the major exploration companies. The Geophysical Section of the Bureau is the only organisation of its kind in Australia, and it has been responsible for the major portion of the geophysical exploration so far under. taken in that country. It is noteworthy that the discoveries made to date have been almost entirely at or near points where important outcropping mineralization had previously been found by ordinary prospecting methods. The task of extending search 
away from known mines has commenced only in the very recent past, and the possibility of the extension of known mineralized structures below thin non-mineralized rock cover is only now being considered.

In the course of the discussion that followed the presentation of these papers, accounts were given of the application of modern methods of mineral prospecting in the British Colonies and in India, and several speakers emphasized that, although applied geophysics is an instrument of great value, a very close collaboration between the geologist and the geophysicist is essential in order to obtain the best results.

F. DiXfeY

${ }^{1}$ C.2. "Modern Methods of Mineral Exploration in South Africa." By Louis T. Nel, D. J. Simpson and John De Villiers. C.3. "Mineral Exploration in Australia." By C. J. Sullivan. C.4. "Modern Joubin.

${ }^{2}$ C.1. "Aerial Photography in Petroleum and Mineral Prospecting." By A. A. Fitch, D. F. Christie, W. E. Johnstone and G. Whittle. 230

\section{ANTHROPOLOGY AND ART}

\section{BY WILLIAM FAGG}

$\mathrm{T}$ HE exhibition of "Traditional Art of the British Colonies" at the Royal Anthropological Institute, 21 Bedford Square, London, W.C.1, which I have had the privilege f arranging, has now been extended until Aagors and is open during 10 a.m. -7 p.m. every fay except Sunday. It is perhaps one of the few serious attempts so far made in Great Britain to rec foile in an exhibition the supposedly conflicting distplines of art and anthropology, and provides a useful occasion to consider whether they are not fundamentally compatible and complementary in much the same way as, for example, religion and science. The great Wilberforce-Huxley controversy of the nineteenth century has long ceased to excite much heat, as divines and savants have equally learned to respect each other's fields ; and it is time that artists and anthropologists made the concessions which would enable them to work together for fuller understanding of the highest manifestations of man's genius.

The present exhibition is not a general survey of primitive art, but is confined in the first place to the colonies administered by the British Colonial Office (Australian and New Zealand Colonies being thereby excluded, and with them the magnificent arts of New Guinea and New Ireland); and secondly, with a very few exceptions, to representational as distinct from decorative art, that is, to figures and masks rather than to 'applied' and geometrical carving. The areas represented are therefore the Solomon and Santa Cruz Islands, the New Hebrides in Melanesia, Fiji and, in Polynesia, the Tonga Group; Sarawak, Brunei and Malaya; of the New World Colonies, British Guiana; and, pre-eminently, Nigeria, by far the most fertile in art of all the British Colonies, while the Gold Coast, Sierra Leone and Tanganyika are also represented. An equally good selection might perhaps have been made of works from the French or the Belgian Colonies; but it would have been difficult indeed to raise the standard of quality, however widely the scope of the exhibition had been extended. Apart from a number of pieces lent by the Government of Nigeria, the assemblage is drawn from British private collections, and none of the pieces is therefore accessible in the ordinary way to the British public, though comparable examples of some of the styles might be found in the British Museum.
The purpose of the exhibition is twofold : first, as a contribution to the "Colonial Month", to demonstrate that, in the field of art at least, many of the Colonial peoples have quite as much to teach us as to learn from us, that though they are behind us in material progress, their greater bent for the things of the spirit has enabled them to produce many sculptural masterpieces which equal or eclipse much of the best work of ancient and modern Europe; and secondly, to interest both artists and anthropologists (as well as the art-loving public) in the common ground between them and encourage that collaboration which is essential if some of the most difficult problems are to be resolved.

The problem with which the inquiring viewer of the exhibition will find himself most squarely faced is that presented by the ancient bronzes and terracottas of Ife, the religious centre of the Yoruba tribe of south-west Nigeria. He will see, side by side, first, the five terra-cottas (the heads of four men and a ram) recently discovered near Ife, more perfect in their idealized naturalism than almost anything in classical Greece or the Renaissance, and dating probably from the twelfth to fourteenth centuries A.D. ; and secondly, a series of wooden masks, still carved and used by the Kalabari Ijo of the Niger Delta, and conveying the idea of the power of the water spirits through a stark and uncompromising stylization. Two styles could scarcely be more diametrically opposed, formally and fundamentally, than these; and it must be said that the Ife style appears distinctly intrusive in the African conception of art. The Ife sculptors sought to present the whole man, perfect by the standards of anatomical mensuration, whereas their successors at Benin and all other Negro tribes (with a few partial exceptions) selected certain qualities and aspects for special emphasis at the expense of the others, and would have thought it inartistic to include matter irrelevant to the idea of a man, or of a spirit, which they wished to present. Thus the Ibo sculptor at Aba who set out to carve the head of an 'elephant spirit' (No. 47 in this exhibition) to symbolize masculine violence and the ugliness of unrestrained power (contrasted with the 'maiden spirit' of gentleness and beauty, in a play on the theme of "Beauty and the Beast") mixed spaces with projecting masses in depth in order to portray that unrelieved ferocity which does not occur in Nature, because every man is a compound of many qualities-good as well as bad-and only art can liberate one from the others. It seems clear that the African artist in general does not entertain the conception of the whole man (as seen at Ife) as an initial stage in working towards his ultimate selective idea of a man; on the contrary, this idea is the very germ and starting point of his creation, with which life-like naturalism has nothing to do.

Here then is the mystery of Ife : Are we to conclude that distortion of Nature not merely is the norm, but is of the invariable essence of 'Africanism' in artin which case we shall have to regard the Ife sculptures as the products of aliens? Or can we set a limit to racial determinism and admit the possibility that the naturalistic approach and 'intellectual vision' might arise-or be maintained through several centuries after introduction from outside-among Africans if the circumstances were favourable enough ? This is a question to which the objective man of science must offer no dogmatic answer; the evidence is incon. clusive enough to require him to keep his mind open. Where he fears to tread, the subjective artist may, 